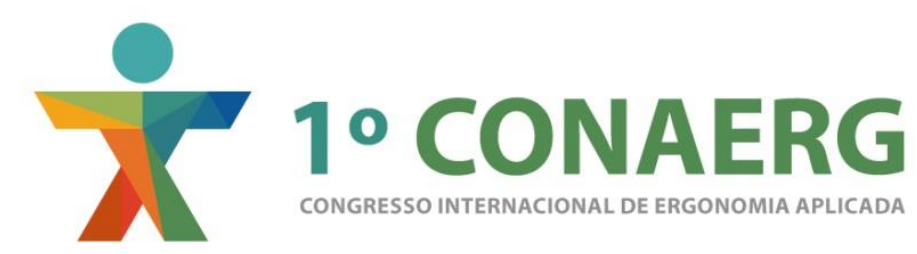

\title{
PERCEPÇÃO DE DESCONFORTO NO USO DE DISPOSITIVO PARA TRANSPORTE DE CARGAS MANUAIS - DESIGN DE ALÇA UNIVERSAL PARA SACOLAS DE COMPRAS
}

\author{
Rodolfo Nucci Porsani (1) \\ Danilo Corrêa Silva (2) \\ Luiz Antônio Vasques Hellmeister (3) \\ Fausto Orsi Medola (4) \\ Luis Carlos Paschoarelli (5) \\ (1) PPGDesign-UNESP, Designer \\ e-mail: rodolfonporsani@gmail.com \\ (2) PPGDesign-UNESP, Doutorando em Design \\ e-mail: danilo@idemdesign.net \\ (3) UNESP - Depto. Artes e Representação Gráfica, Doutor em Engenharia Rural \\ e-mail: hellmeister@faac.unesp.br \\ (4) PPGDesign-UNESP, Doutor em Bioengenharia \\ e-mail: fausto-medola@faac.unesp.br \\ (5) PPGDesign-UNESP, Livre-docente em Design Ergonômico \\ e-mail: paschoarelli@faac.unesp.br
}

\begin{abstract}
O presente paper demonstra o desenvolvimento de um produto, por processo colaborativo entre dois grupos de pesquisa, com a associação entre tecnologia de prototipagem rápida de manufatura aditiva e avaliação ergonômica de percepção. Uma alça para sacolas plásticas foi desenvolvida e comparada com outras alças e a própria sacola plástica (controle). A avaliação laboratorial envolveu a aplicação de testes cegos e método DS e a escala de Likert para avaliação de satisfação com usuários. Os resultados apontam que a alça desenvolvida apresentou melhores condições ergonômicas de uso e demonstram que a avaliação do protótipo durante o desenvolvimento do produto amplia a usabilidade dos produtos gerados.
\end{abstract}

It is an empirical practical work character based on two main concepts, the development of a product for collaborative process within the academic community, linking the Project Extension Difusão and Laboratory of Ergonomics and Interfaces ( LEI) UNESP - Bauru and the use of rapid prototyping technology of additive manufacturing, popularly known as 3D printing, production of inexpensive prototypes focused on laboratory evaluation with users through blind tests with sensor gloves, visual tests with application of the DS method, and Likert scale to assess satisfaction in controlled simulation. 


\section{INTRODUÇÃO}

O presente estudo se caracteriza pela abordagem do Design Ergonômico, cuja proposição é a aplicação do conhecimento ergonômico no projeto de dispositivos tecnológicos, com o objetivo de alcançar produtos e sistemas seguros, confortáveis, eficientes, efetivos e aceitáveis (PASCHOARELLI, 2003). Neste sentido, trata-se do relato de uma abordagem empírica, de caráter prática, fundamentado em dois processos. O primeiro é o desenvolvimento de projeto de produto, através da cooperação entre o Projeto de Extensão Universitária "Difusão" e os estudos desenvolvidos no Laboratório de Ergonomia e Interfaces (LEI) da UNESP-Bauru. O outro dá-se pelo uso da tecnologia de prototipagem rápida de manufatura aditiva, popularmente conhecida como impressão 3D, na produção de protótipos de baixo custo voltados à avaliação volumétrica e testes laboratoriais com usuários.

A prototipagem rápida, enquanto tecnologia 3D, começou a ser desenvolvida a partir da topografia e foto-escultura (Volpato 2007). Hoje existem três principais tipos de tecnologia de Impressão 3D: líquida, sólida e a pó. Sua principal característica é a materialização do objeto projetado, por meio de camadas adicionadas umas sobre as outras, o que possibilita o desenvolvimento de objetos de elevada complexidade e resolução.

A problemática abordada dá-se pelo desenvolvimento de um protótipo de alça universal para sacolas de compras, utilizadas por clientes de mercados, lojas, e demais setores comerciais. $\mathrm{O}$ artefato foi criado para garantir um maior conforto no transporte de cargas manuais, possibilitando um carregamento de maior peso, por maior tempo e por uma maior distância. Neste sentido, visa facilitar a vida diária do usuário e evitar o desconforto causado pelas alças das sacolas plásticas sobre a face palmar (especialmente na região das falanges).

As justificativas para a realização deste estudo são as necessidades de avaliar uma ideia materializada e verificar se o produto desenvolvido apresenta-se adequado, sob o ponto de vista da ergonomia. Portanto, seu objetivo foi analisar a percepção de uso do produto desenvolvido para transporte de cargas manuais, bem como estudar as relações entre o design deste dispositivo e os aspectos prático-funcionais e ergonômicos.

\section{FUNDAMENTAÇÃO TEÓRICA}

\subsection{Aspectos Ergonômicos}

O comércio brasileiro, particularmente o setor de varejo - em especial, os denominados "supermercados" - apresenta ampla participação nas atividades econômicas, especialmente junto à população urbana e dos grandes centros. E o transporte das compras, realizados pelos consumidores a partir dos check-outs, ocorre habitualmente com o uso de sacolas plásticas, de baixo custo e relativa funcionalidade.

Tais sacolas já foram amplamente questionadas, especialmente pelo elevado impacto ambiental que apresentam no pós-uso. Entretanto, novas tecnologias de materiais desenvolveram plásticos biodegradáveis, o que minimizou o problema observado. Para além disto, o principal problema do uso de sacolas plásticas está na consequência ergonômica que o transporte manual deste produto acarreta.

Segundo Gonçalves (1998), o "ato de levantar um peso está incluído muitas vezes nos movimentos que realizamos durante todo o dia. Mesmo que sua massa seja pequena, realizamos este levantamento manual de carga muitas vezes automaticamente, sem que tenhamos consciência dos mecanismos de exigência sobre o organismo necessários para que esta carga possa ser elevada ou sustentada" (p. 85 MOTRIZ - Volume 4, Número 2, Dezembro/1998). No caso do transporte das sacolas plásticas, por ser uma atividade rotineira e diária e, na maioria das vezes, sem consciência da forma correta de execução, o indivíduo 
pode se lesionar com o passar do tempo, não apenas quanto às questões posturais, mas e principalmente - quanto à pressão exercida na face palmar, especialmente na região das falanges.

Particularmente, com relação à pressão exercida na face palmas das mãos, não foi encontrado qualquer estudo que realizasse uma avaliação durante o uso (pega/transporte) de sacolas plásticas. Independentemente deste fator, a avaliação das forças de pressão de contato é uma importante variável na identificação de potenciais problemas biomecânicos e ergonômicos em atividades manuais. Seus resultados possibilitam indicar quais aspectos morfológicos das interfaces dos instrumentos manuais induzem à pressão indesejada nas faces palmares e nos tecidos internos da mão humana.

Tichauer e Gage (1977) afirmam que elevadas pressões exercidas em pontos frequentes da região palmar podem comprimir artérias, veias e nervos, e resultar em lesões que poderão ser irradiadas para outras regiões anatômicas da mão. Hall (1997) reitera que as propriedades da superfície do instrumento manual apresentam uma grande influência nos pontos de pressão exercidos sobre as mãos; o que é corroborado por Muralidhar et al. (1999), quando afirmam que a distribuição de força aplicada sobre a superfície palmar não é uniforme em nenhuma atividade manual, assim como o risco relativo de traumas biomecânicos. Portanto, identificar e mensurar tais pressões é fundamental para a avaliação e análise ergonômica de atividades manuais. Ainda, de acordo com Cacha (1999), as pressões exercidas por objetos com pequena superfície, podem causar isquemias, minimizando a circulação sanguínea local.

No Brasil, estudos que trataram desta variável foram desenvolvidos por Paschoarelli e Gil Coury (2004); e tecnologias para a avaliação desta variável foram descritas por Silva et al. (2008).

\subsection{Processo Projetual aplicado no desenvolvimento da Alça}

Os problemas ergonômicos gerados pelo transporte manual de sacolas plásticas podem não ser representativos do ponto de vista econômico (tal qual é observado nas atividades ocupacionais), mas parece ser um incômodo para usuários, especialmente se consideradas as amplas implicações que a ergonomia tem nas atividades cotidianas da vida diária.

Neste sentido, e tendo por princípio as contribuições do design ergonômico (relatado anteriormente), optou-se por desenvolver um novo produto, particularmente uma alça que distribui as cargas geradas pelas alças de sacolas plásticas sobre a face palmar do usuário. Tal inovação baseia-se na conjectura de Baxter, em sua obra. "Projeto de Produto: Guia Prático para o Design de Novos Produtos" (2005, p.1), o qual afirma ser "... um ingrediente vital para o sucesso dos negócios".

Dentro desta perspectiva, e considerando as metodologias de desenvolvimento de projeto de produto descritas por Bonsiepe em suas obras "Um Experimento em Projeto de Produto: Desenho Industrial"(1983), "A Tecnologia da Tecnologia (1983) e "Metodologia Experimental: Desenho Industrial" (1984) , a quais indicam a "experimentação" como alternativa metodológica, foram desenvolvidas várias alternativas de objetos (Figura 1); definido um conceito para o novo produto (Figura 2); e consequente protótipo, produzido por meio da tecnologia de manufatura aditiva, também conhecida como impressão 3D(Figura 3). 
Figura 1 - Alternativas (sketches) desenvolvidas para o novo produto.

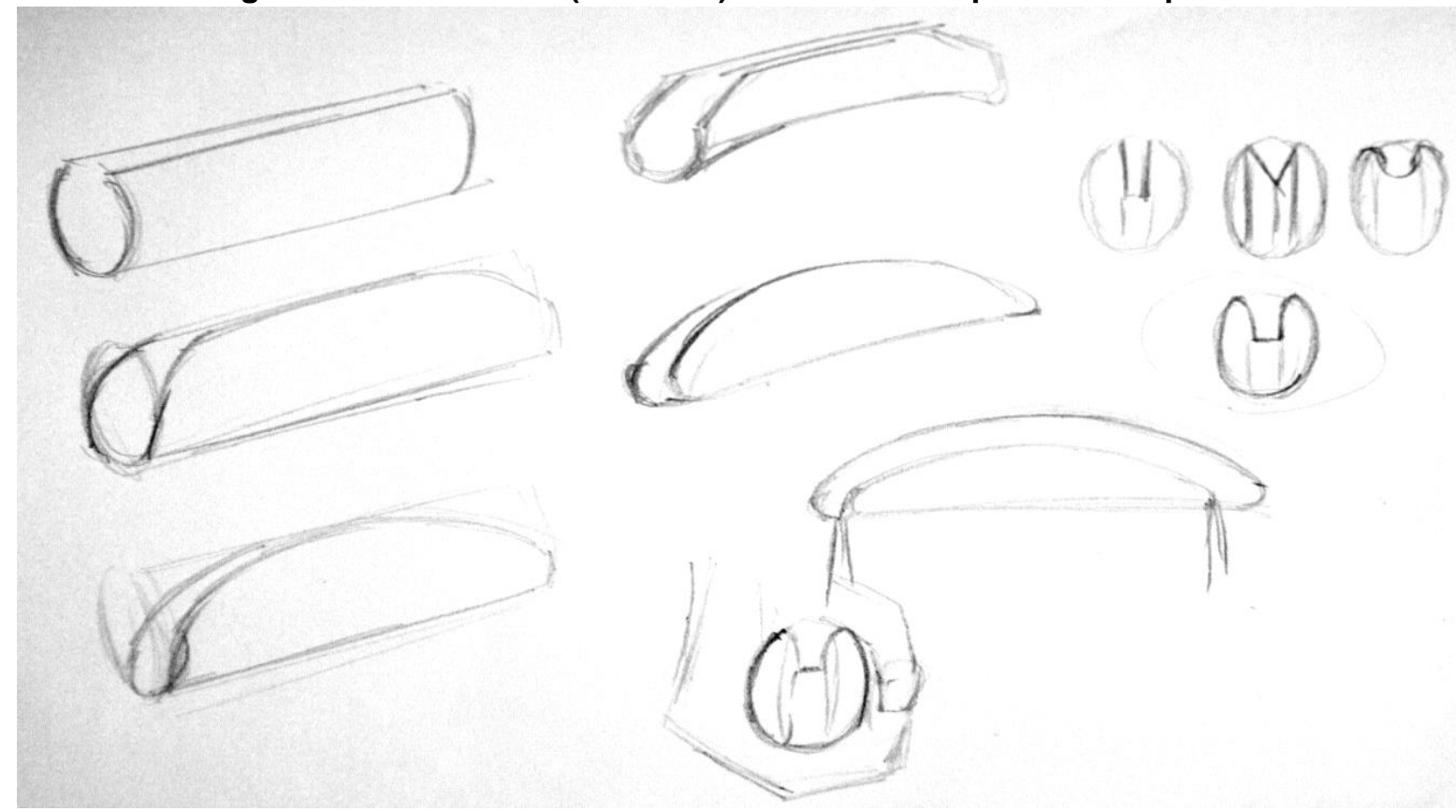

Fonte: Elaborada pelos Autores (2016).

Figura 2 - Alternativa de conceito escolhida, modelada tridimensionalmente (3D).
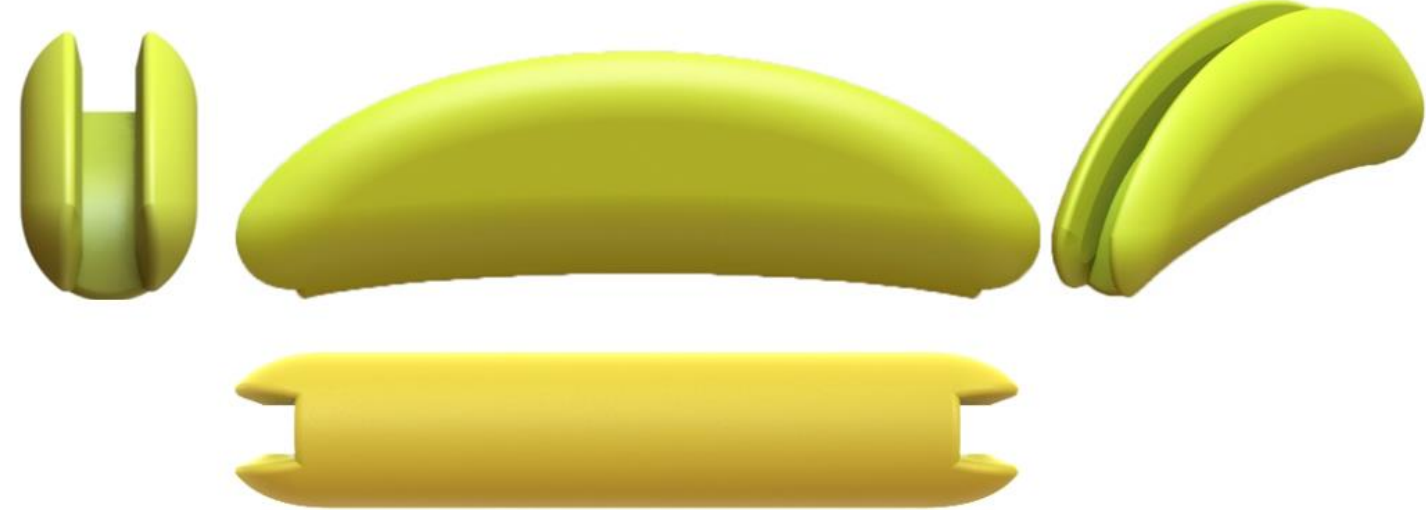

Fonte: Elaborada pelos Autores (2016).

Figura 3 - Protótipo gerado por prototipagem rápida em impressão 3D - ABS (acabamentos e pinturas manuais).

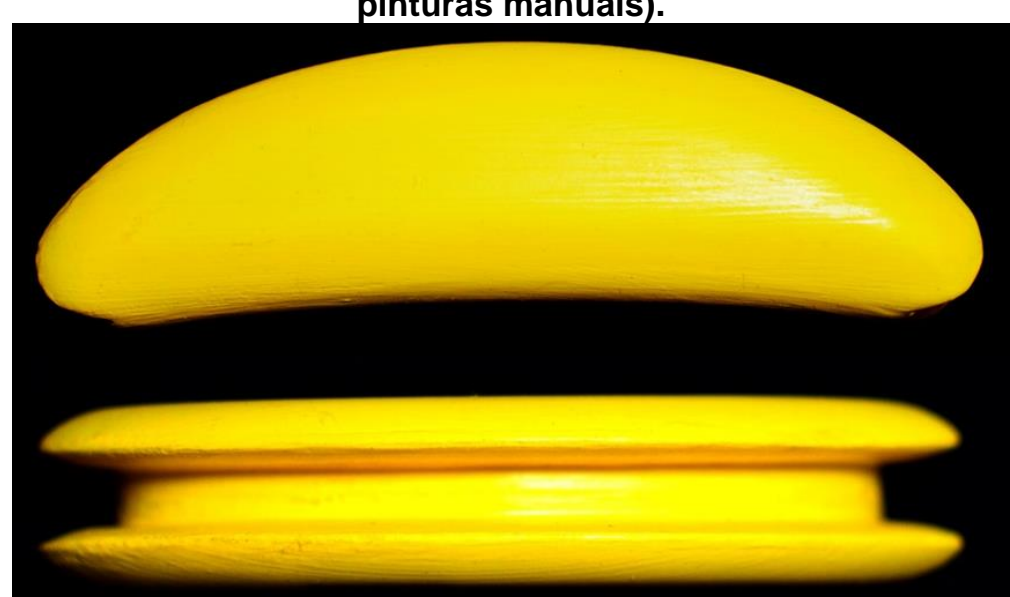

Fonte: Elaborada pelos Autores (2016). 


\section{MATERIAIS E MÉTODOS}

\subsection{Características do Estudo e da Amostra}

O presente estudo foi realizado na Sala de Experimentos do Laboratório de Ergonomia e Interfaces da UNESP - Campus Bauru. Tratou-se de uma abordagem transversal, caracterizada pela simulação de uso do produto, por sujeitos adultos e saudáveis. Por se tratar deste tipo de abordagem, foi utilizado um Termo de Consentimento Livre e Esclarecido (TCLE), atendendo à Resolução 196/96-CNS-MS e à Norma ERG BR 1002, do Código de Deontologia do Ergonomista Certificado (ABERGO, 2003). O preenchimento e assinatura do participante no TCLE representava que o mesmo estava apto e aceitou sua participação.

Participaram 08 (oito) indivíduos voluntários, todos destros e adultos, com idade média de 23,9 anos (d.p. 3,5), estatura média de $171,3 \mathrm{~cm}$ (d.p. 7,9) e peso médio de 70,4 $\mathrm{Kg}$ (d.p. 14,4). 04 (quatro) indivíduos eram do gênero masculino, com idade média de 22,3 anos (d.p. 2,2), estatura média de $176,5 \mathrm{~cm}$ (d.p. 6,7) e peso médio de 75,0 Kg (d.p. 17,3); e 04 (quatro) indivíduos eram do gênero feminino, com idade média de 25,5 anos (d.p. 4,0), estatura média de 166,0 cm (d.p. 5,2) e peso médio de 67,0 Kg (d.p. 13,3).

Nenhum dos sujeitos relatou a ocorrência de distúrbios musculoesquelético nos membros superiores (sendo este, um dos fatores de inclusão na amostra). As dimensões das mãos também foram obtidas, afim de caracterizar o aspecto antropométrico da amostra (Figura 4).

Figura 4 - Característica antropométrica da mão dos participantes.

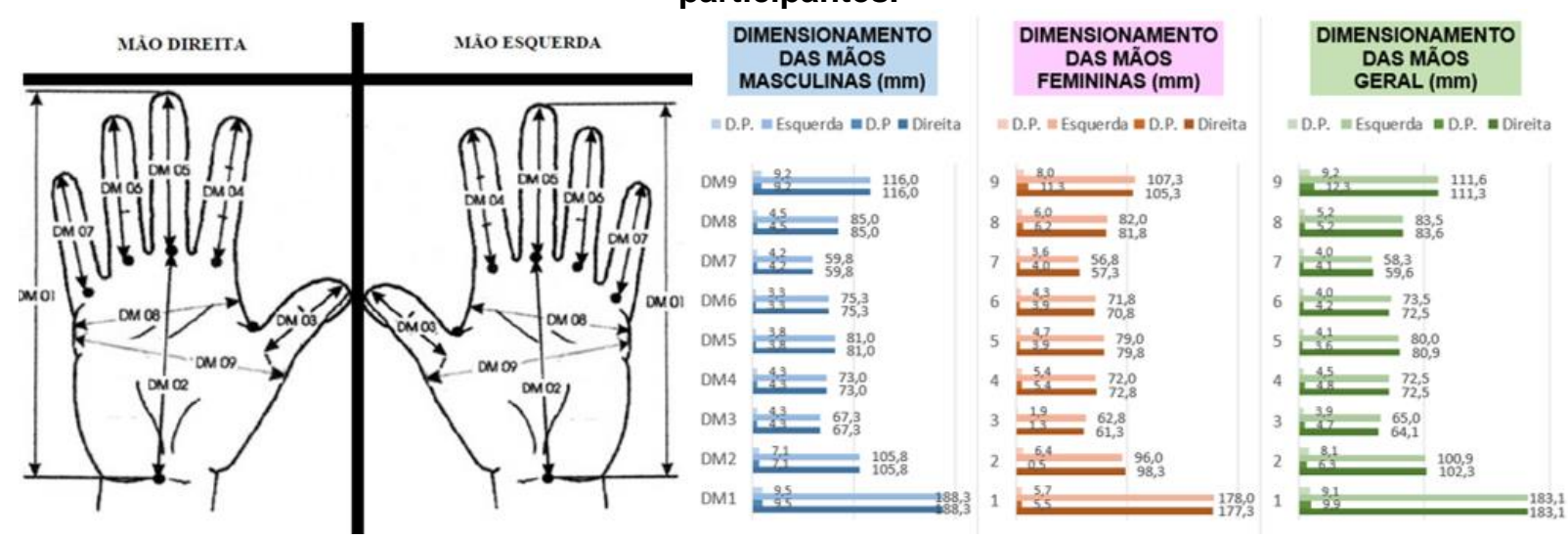

Fonte: Elaborada pelos Autores (2016).

\subsection{Instrumentos de Análise}

Além do TCLE, foi também aplicado um protocolo de identificação dos participantes (com dados gerais) para cadastro dos mesmos. Um protocolo de Avaliação de Desconforto, com escala de 7 (sete) pontos, variando de "Máximo Desconforto" até "Ausência de Desconforto". Um protocolo de Diferencial Semântico de 10 pares de adjetivos antagônicos, com 7 âncoras (baseadas na Escala de Likert) foi aplicado, afim de identificar diferenças perceptivas entre os objetos avaliados. E uma escala de satisfação, variando de 1 (menor satisfação) a 4 (maior satisfação) foi desenvolvido e aplicado, para que os participantes disponibilizassem os modelos, segundo sua percepção.

Para obtenção de dados antropométricos foi utilizado uma balança eletrônica com antropômetro; e um scanner para digitalização das mãos, direita e esquerda, de cada participante, para obtenção de dados por meio de biofotogrametria. Para a realização dos testes "cego", foi utilizado uma venda (para os olhos) em tecido preto. E para a avaliação dos produtos, propriamente dito, foram utilizados 04 (quatro) diferentes interfaces, sendo 1 (um) controle e 3 (três) protótipos de dispositivos de transporte (Figura 5). 
Figura 5 - Protótipos Utilizados
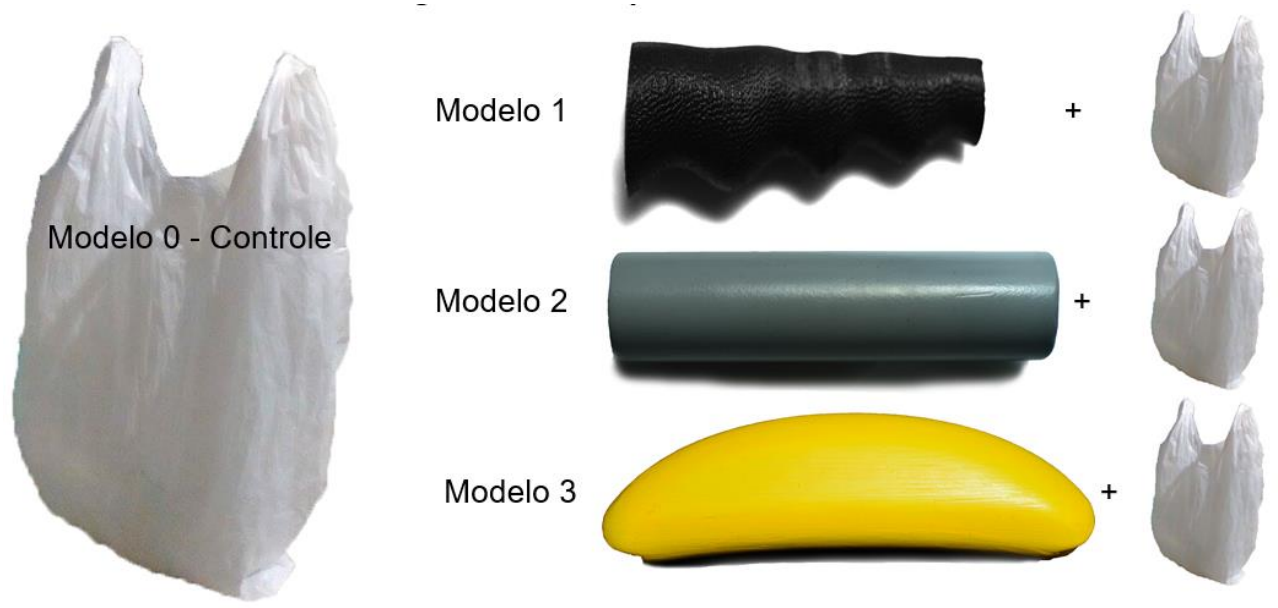

Fonte: Elaborada pelos Autores (2016).

\subsection{Procedimentos}

Os participantes (voluntários) se apresentaram no ambiente de pesquisa e leram, preencheram e assinaram o TCLE. Em seguida um protocolo de identificação foi aplicado e foram coletados os dados antropométricos (peso, estatura, idade e escaneamento das mãos).

Na sequência, cada participante individualmente foi conduzido à um teste (avaliação) cego de percepção de conforto com peso padrão de 3 (três) quilogramas dispostos dentro de uma sacola plástica (Modelo 0 - Controle), comumente encontrada em mercados. Neste caso, os indivíduos seguraram as interfaces por um tempo padrão de 30 (trinta) segundos. A distribuição das diferentes interfaces seguiu uma ordem randomizada. Em seguida, os participantes indicavam no protocolo de Avaliação de Desconforto qual o nível foi percebido para cada interface. Um intervalo de 60 segundo foi utilizado entre as atividades. Na etapa seguinte, foram aplicados protocolos de Diferencial Semântico, igualmente organizados em sequências randômicas. Foram disponibilizados os modelos utilizados durante a etapa anterior para analise em mãos dos voluntários (Figura 6).

Figura 6 - Aplicação do protocolo de Diferencial Semântico com cada uma das interfaces avaliadas.

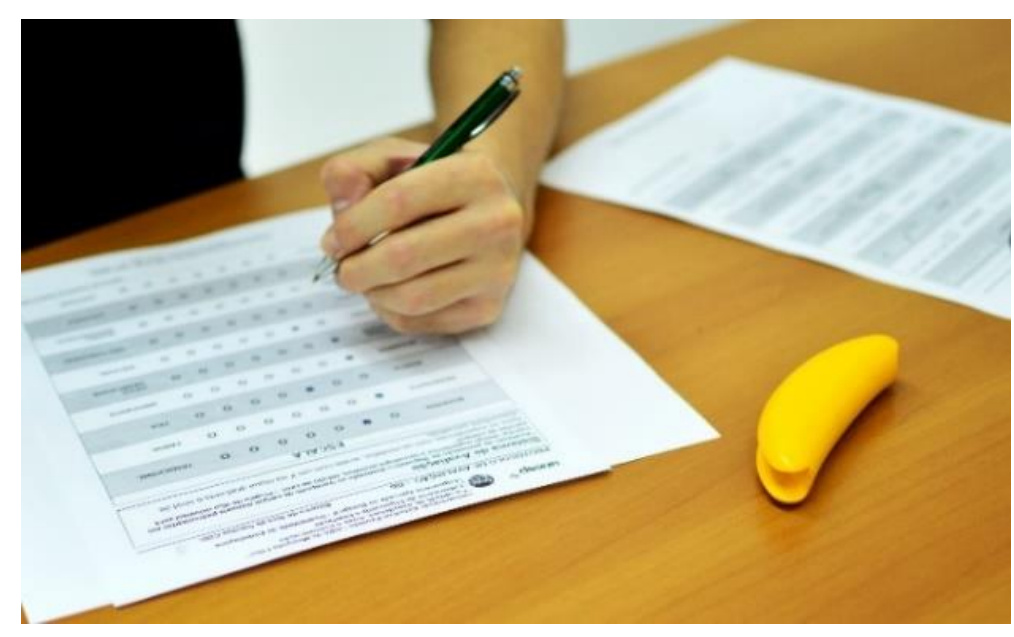

Fonte: Elaborada pelos Autores (2016) 
Após a aplicação do protocolo de Diferencial Semântico, foi proposto aos voluntários uma simulação de uso dos dispositivos dispostos de ordem aleatória sob a mesa, sugerindo que o usuário escolhesse o dispositivo desejado, implantasse a sacola com o peso padrão de três quilos e percorresse o trajeto delimitado no chão, cinco metros de ida e cinco metros de volta (Figura 7).

Ao final da simulação com os 3 dispositivos e com o controle foi aplicado a cada voluntário um teste baseado na escala de Likert, com quatro lacunas com pontuação de 1 a 4 onde 0 usuário dispôs cada modelo de acordo com os níveis de menor satisfação 1 ponto a maior satisfação 4 pontos (Figura 8), encerrando a coleta laboratorial.

Figura 7 - Simulação de Uso.

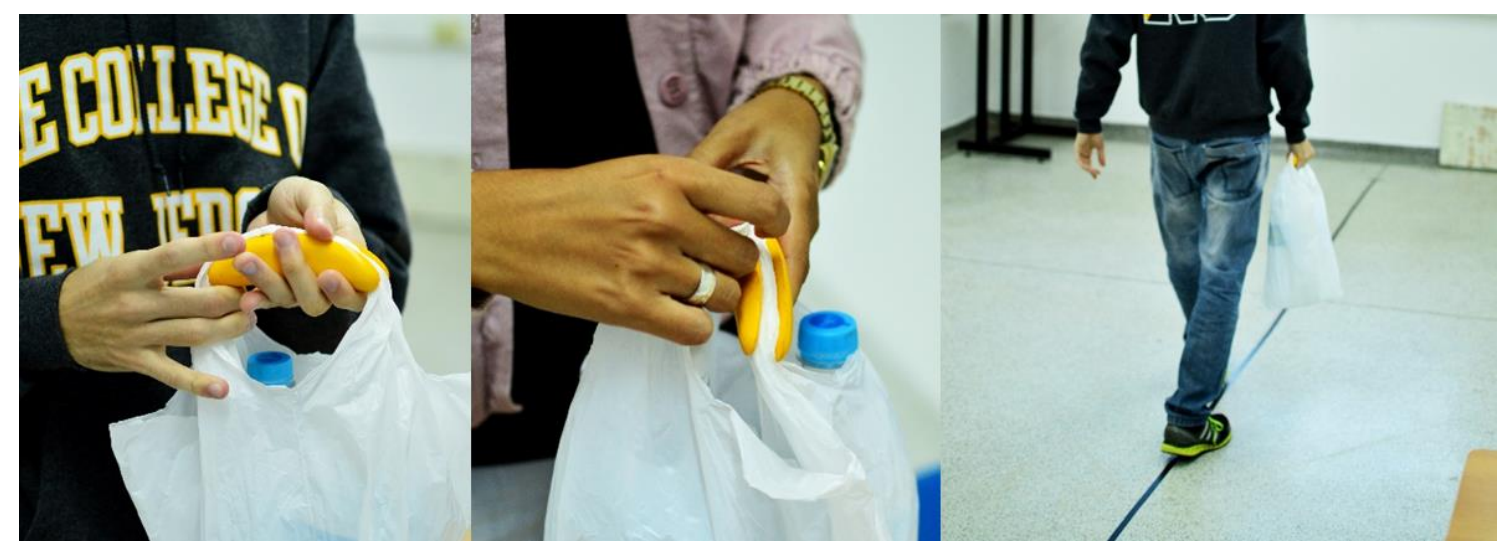

Fonte: Elaborada pelos Autores (2016)

Figura 8 - Teste de Satisfação após Simulação.

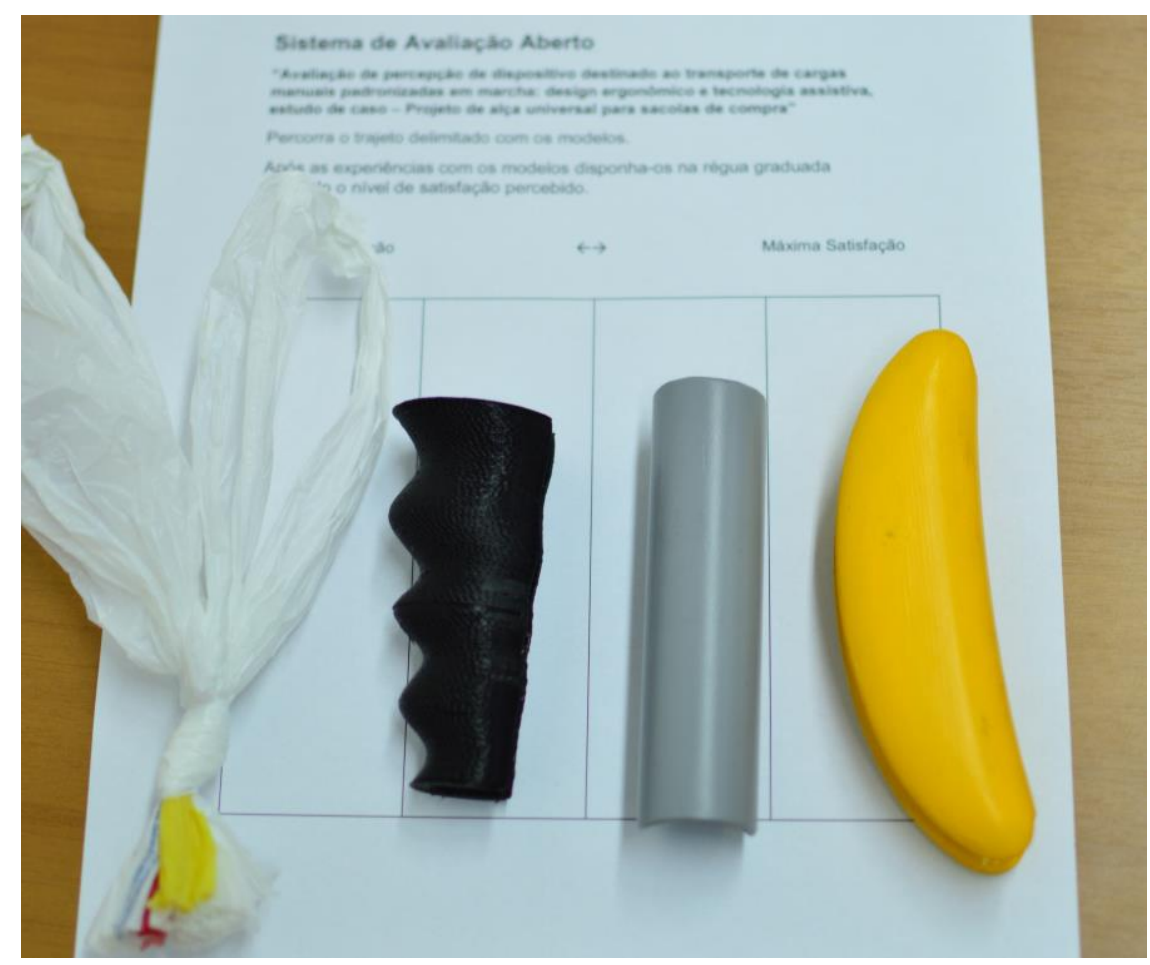

Fonte: Elaborada pelos Autores (2016) 


\section{RESULTADOS}

\subsection{Teste Cego}

Os resultados do Teste Cego podem ser observados na Figura 9. Observa-se que a condição CONTROLE caracterizou-se pelos maiores níveis de desconforto $(-2,10)$, possivelmente por possuir menor área de contato em relação à mão, causando uma concentração de peso, sobre uma pequena região nas faces palpares das falanges.

O Protótipo 1 apresentou nível de conforto igual a "0,0" (zero); o Protótipo 2 apresentou nível de conforto igual a "1,50" (um e meio) e o Protótipo 3 apresentou nível de conforto igual a "2,00" (dois inteiros), sendo classificado como o mais confortável devido a sua melhor pega, maior área de contato e melhor distribuição de peso.

Figura 9 - Resultados do Teste Cego.

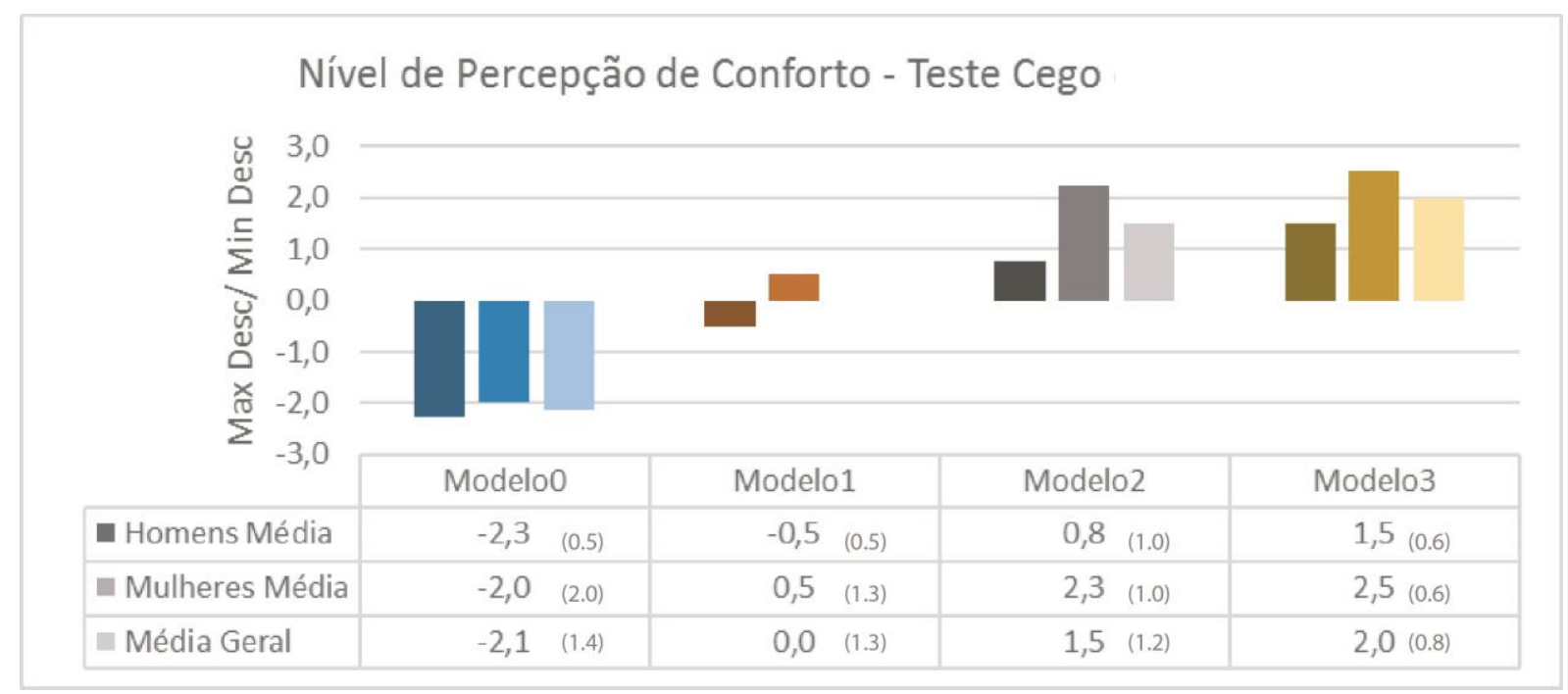

Fonte: Elaborada pelos Autores (2016)

\subsection{Diferencial Semântico}

Os resultados de Diferencial Semântico podem ser observados na Figura 10. Tais dados apresentaram semelhanças, tanto entre os participantes do gênero masculino quanto no feminino. O Controle apresentou o nível de maior reprova, com média geral -1,66 pontos, os Modelos 1 e 2 mostraram-se semelhantes entre si com melhor pontuação em relação ao controle: nos resultados de Modelo 1, a média geral foi 0,51 pontos; e no Modelo 2, a média geral foi 0,65 pontos. O Modelo 3 mostrou-se superior às demais interfaces, com média geral de 1,75 pontos.

Nota-se na Figura 10, que a linha identificadora do Controle se destaca negativamente em relação a todos os 3(três) protótipos analisados, direcionando-se à esquerda. Os 3 (três) protótipos analisados Modelo 1, Modelo 2 e Modelo 3 demonstraram-se melhor avaliados em relação ao Controle, e dentre eles o Modelo3 destacou-se positivamente, mantendo-se à direita. 
Figura 10 - Resultados da Aplicação do Diferencial Semântico.

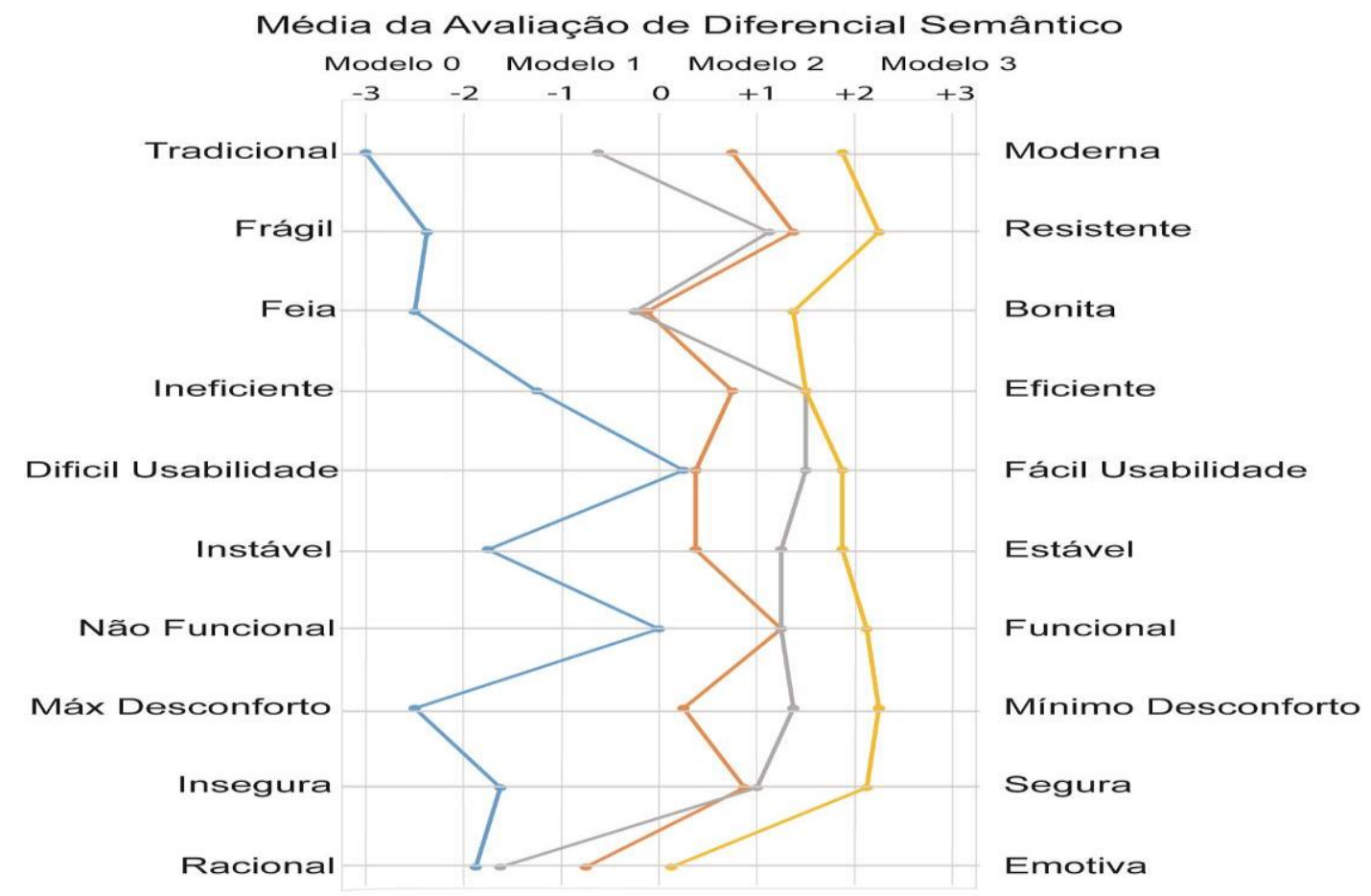

Fonte: Elaborada pelos Autores (2016)

\subsection{Nível de Satisfação}

Os resultados do nível de satisfação podem ser observados na Figura 11. A interface controle apresentou o nível de maior reprova, com média geral 1,00 pontos, os Modelos 1 e 2 mostraram-se com melhor pontuação em relação ao controle, com os resultados de Modelo 1 média geral 2,25 pontos; e o Modelo 2 com média geral de 3,00 pontos. O Modelo 3 novamente mostrou-se superior à seus concorrentes, com média geral de 3,75 pontos.

Figura 11 - Avaliação de Nível Satisfação após Simulação de Uso

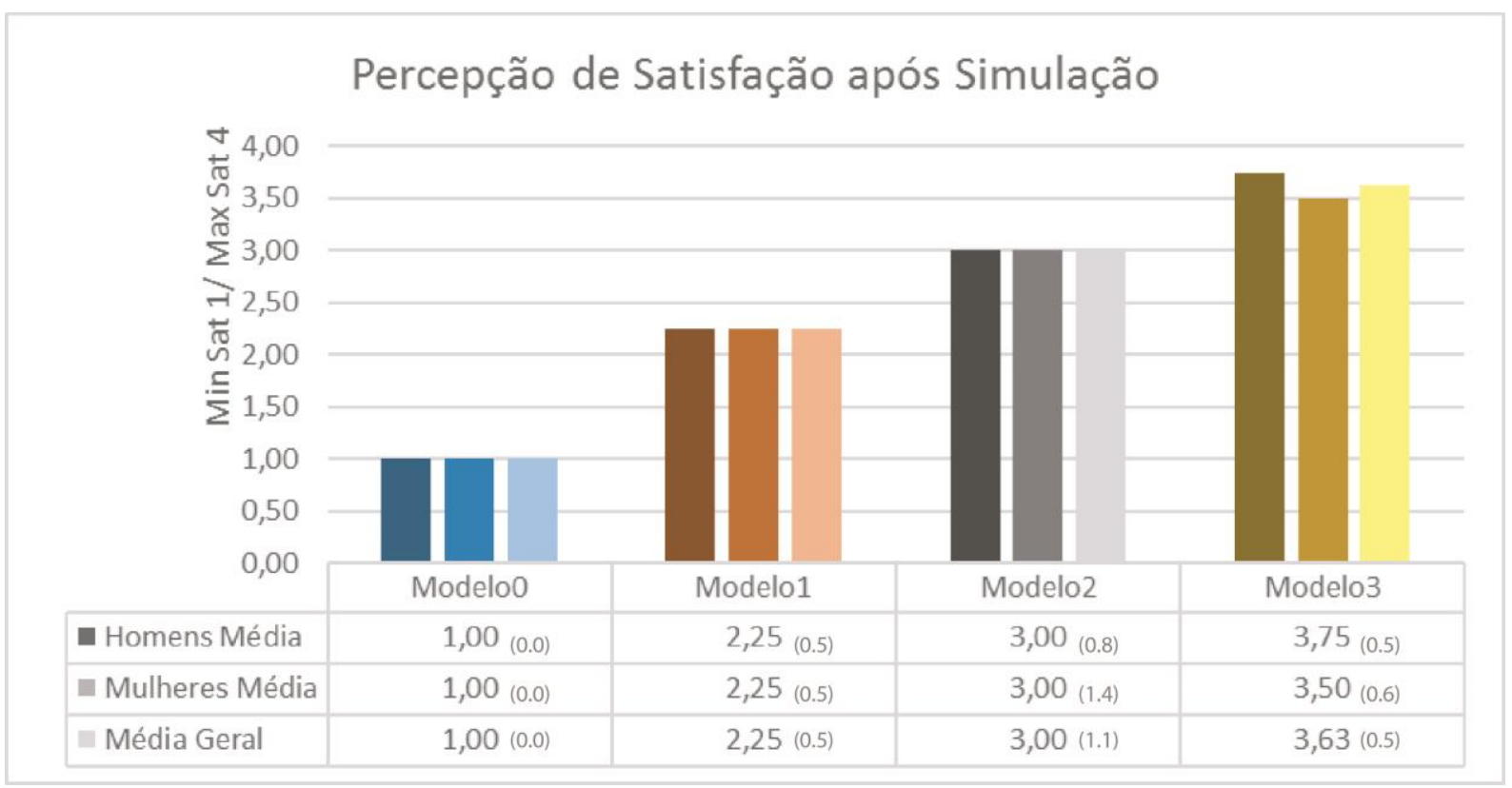

Fonte: Elaborada pelos Autores (2016) 


\section{DISCUSSÃO E CONSIDERAÇÕES FINAIS}

Atividades cotidianas, realizadas de modo habitual, passaram a fazer parte dos estudos da ergonomia, especialmente após o final do Século XX. Na ocasião percebeu-se que esta área do conhecimento poderia atender as demandas físicas e cognitivas de diferentes tarefas e atividades humanas (e, não apenas, aquelas de ordem ocupacional).

O transporte manual de cargas foi amplamente estudado pela ergonomia, mas quando se trata da realização de atividades cotidianas - como é o caso do transporte de sacolas plásticas - ainda não existem estudos que abordam esta problemática.

O presente artigo relata a avaliação de 3 (três) diferentes interfaces projetadas para facilitar o transporte de sacolas plásticas - além da própria sacola em si. A partir da realização de atividades simuladas de transporte e procedimentos metodológicos controlados especialmente com o uso de escalas de percepção - foi possível avaliar as 4 (quatro) interfaces de uso.

Os resultados apontam que o uso de uma alça (Modelo 3) proporciona as melhores condições ergonômicas. Considerando o design desta alça (Modelo 3), pode-se deduzir que a forma planejada proporciona melhor distribuição de cargas na face palmar. Para se confirmar isto, é necessário realizar uma avaliação física da situação, utilizando sensores específicos. Para além disto, observa-se que tal avaliação não apenas identificou (sob o escopo da percepção do usuário) qual o melhor design de alça destinado à função prescrita, mas (e, principalmente), possibilitou agregar um método de avaliação ergonômica (com base na percepção do usuário) adequado e robusto, a ser aplicado durante o desenvolvimento de projetos de produto.

É nesta circunstância que o presente estudo é uma demonstração aplicada do Design Ergonômico, uma vez que disponibiliza o conhecimento sobre procedimentos metodológicos de avaliação e design de produtos.

\section{AGRADECIMENTOS}

Agradecimentos especiais à FAPESP (Proc. 2013/24629-5).

\section{BIBLIOGRAFIA}

ABERGO. Norma ERG BR 1002 - Código de Deontologia do Ergonomista Certificado. Associação Brasileira de Ergonomia, 2003.

IIDA, I. Ergonomia: projeto e produção. São Paulo: Edgard Blücher, 1990

GRANDJEAN, E. Manual de ergonomia: adaptando o trabalho ao homem. Porto Alegre: Bookman, 1998.

FUNDACENTRO - Levantamento e transporte manual de pesos. São Paulo, FUNDACENTRO, s/d.

GONÇALVES, M. Levantamento manual de carga: efeito da postura, altura e uso de cinto. Tese de doutorado em Anatomia, ICB, USP, SP, 1996. P 
PASCHOARELLI, L. C.; COURY, H. J. C. G. O uso do FSR na avaliação de preensão de instrumentos manuais: uma alternativa metodológica para o design ergonômico de empunhaduras. In: Anais do P\&D DESIGN 2004 - VI Congresso Brasileiro de Pesquisa e Desenvolvimento em Design. São Paulo: AenD-BR / FAAP, 2004.

SILVA, D. C.; PASCHOARELLI, L. C.; POUSSEP, S. Utilização de luvas instrumentadas em avaliações biomecânicas da preensão da mão humana. In: Anais do 8을 Congresso Brasileiro de Pesquisa e Desenvolvimento em Design. São Paulo: Associação de Ensino e Pesquisa de Nível Superior de Design do Brasil, 2008. v. 1. p. 1018-1030.

CACHA, C.A. Ergonomics and safety in hand tool design. New York: Lewis Publishers, 1999, $117 p$.

HALL, C. External pressure at the hand during object handling and work with tools. International Journal of Industrial Ergonomics. 20 (03): 191-206. 1997.

MURALIDHAR, A.; BISHU, R. R.; HALLBECK, M. S. The development and evaluation of an ergonomic glove. Applied Ergonomics. 30 (06): 555-563. 1999.

TICHAUER, E. R.; GAGE, H. Ergonomic principles basic to hand tool design. American Industrial Hygiene Association Journal. 38 (11): 622-634. 1977.

BAXTER, M. R. Projeto de Produto: Guia Prático para o Design de Novos Produtos. 2. Ed. São Paulo: Editora Blücher, 2005.

BONSIEPE, G. - A Tecnologia da Tecnologia. São Paulo: Ed. Blücher, 1983

BONSIEPE, G. WALKER, R. -Metodologia Experimental: Desenho Industrial. Brasília: CNPq / Coordenação Editorial, 1984.

BONSIEPE, G. WALKER, R. -Um Experimento em Projeto de Produto: Desenho Industrial. Brasília: CNPq/Coordenação Editorial, 1983.

GONÇALVES, M. - "VARIÁVEIS BIOMECÂNICAS ANALISADAS DURANTE O LEVANTAMENTO MANUAL DE CARGA" - Departamento de Educação Física - UNESP Rio Claro 